\title{
A Quadruped Study on Chitosan Microspheres Containing Atorvastatin Calcium: Preparation, Characterization, Quantification and in-Vivo Application
}

\author{
Hakan Eroglu, ${ }^{*, a}$ Emirhan Nemutlu, ${ }^{b}$ Omer Faruk Turkoglu, ${ }^{c}$ Osman Nacar,${ }^{d}$ Ebru Bodur, ${ }^{e}$ \\ Mustafa Fevzi SARgon, ${ }^{f}$ Etem BeskonakLi, ${ }^{c}$ and Levent $\mathrm{ONER}^{a}$ \\ ${ }^{a}$ Department of Pharmaceutical Technology, Faculty of Pharmacy, Hacettepe University; ${ }^{b}$ Department of Analytical \\ Chemistry, Faculty of Pharmacy, Hacettepe University; ${ }^{e}$ Department of Biochemistry, Faculty of Medicine, Hacettepe \\ University; ${ }^{f}$ Department of Anatomy, Faculty of Medicine, Hacettepe University; 06100 Sihhiye, Ankara, Turkey: \\ ${ }^{c}$ Department of Neurosurgery, Ankara Ataturk Research \& Education Hospital; 06800 Bilkent, Ankara, Turkey: and \\ ${ }^{d}$ Department of Neurosurgery, Ankara Numune Research \& Education Hospital; 06100 Sihhiye, Ankara, Turkey. \\ Received April 8, 2010; accepted May 21, 2010
}

Atorvastatin is commonly used as a cholesterol lowering agent in patients. Recently, the neuroprotective effects of atorvastatin became the focus of many research studies. In this study, we have formulated chitosan microspheres containing atorvastatin calcium. In-vitro characterization of chitosan microspheres and quantification of atorvastatin calcium from formulations were also evaluated. The neuroprotective efficiency of atorvastatin calcium was investigated by an experimental spinal cord injury model. Atorvastatin calcium microspheres were implanted at the laminectomy area $(1 \mathrm{mg} / \mathrm{kg})$ immediately after trauma. Twenty-four hours after injury, motor functions of animals were scored according to modified Tarlov Scale. In spinal cord tissues tumor necrosis factor (TNF)- $\alpha$, interleukin (IL)-1 $\beta$, IL-6 and lipid peroxidation levels were quantified and ultrastructural changes have been investigated. The results of all parameters indicate that microspheres containing atorvastatin calcium were capable of improving functional outcome, attenuating the expression of TNF- $\alpha$, IL-1 $\beta$ and IL-6; lowering lipid peroxidation levels and maintaining the preservation of the cellular uniformity.

Key words microsphere; chitosan; atorvastatin; spinal cord injury; quantification

Spinal cord injury (SCI) is a devastating and complex clinical condition which involves a cascade of events. The intensity of the primary insult basically affects the clinical outcomes; however the secondary injury mechanisms more importantly determine the neurological conditions of the patients. Initial physical insult (primary injury) is followed by a progressive injury process (secondary injury) that leads to tissue destruction, neuronal loss, axonal damage. ${ }^{1)}$ The secondary injury mechanisms start just a few minutes after primary insult and last up to days and months. Current treatments involving high-dose methylprednisolone administration has been more questionable depending on its benefit/risk ratio.

Statins belong to the class of 3-hydroxy-3-methyl-glutarylCoA (HMGCo-A) reductase inhibitors and they are the generally known as cholesterol lowering agents. Besides their well known effects, they are known to be involved in many cellular processes through cholesterol dependent/independent mechanisms. The first pioneering studies for the investigation of their effects in neurodegenerative disorders demonstrated their anti-inflammatory effects in primary astrocytes, ${ }^{2)}$ neuroprotective effects in multiple sclerosis, ${ }^{3-5}$ Alzheimer's disease, ${ }^{6-8)}$ stroke $^{9-11)}$ and spinal cord injury. ${ }^{12,13)}$ Although the underlying mechanisms are not fully clarified, the main possible mechanism suggested is the pleiotropic effects on endothelium dependent vasodilatation, atherosclerotic plaque stabilization, anti-thrombotic, anti-oxidative and anti-inflammatory effects. ${ }^{14-17)}$

Chitosan, $\beta(1,4)$-2-amino-2-deoxy-D-glucose, is one of the major polymers used in pharmaceutical dosage forms. Chitosan is obtained by the alkaline deacetylation of the chitin, which exists in the natural structure of the outer shells of the crustecea. ${ }^{18)}$ The outstanding properties that make chitosan such popular in pharmaceutical filed is its being non-toxic and potentially safe, ${ }^{19)}$ biodegradability and biocompatibility. ${ }^{20-22)}$ Depending on these facts, the major aim of this study was constructed on a quadruped target as starting with the formulation of chitosan microspheres containing atorvastatin calcium, characterization of microspheres, in-vitro quantification of atorvastatin calcium loaded in the microspheres and investigation of the efficiency of these microspheres after administration to rats, which were introduced to the experimental spinal cord injury model.

\section{Experimental}

Materials The atorvastatin calcium used as the active ingredient in this study was from Dr. Reddy's Laboratories (Mumbai, India). The chitosan polymer used for the preparation of microsphere formulations was purchased from Sigma Aldrich (Milwaukee, U.S.A.). Three different types of chitosan were used in the formulation studies. The low molecular weight chitosan with Brookfield viscosity ( $1 \%$ in $1 \%$ acetic acid) of $20 \mathrm{cP}$ and deacetylation degree of $75-85 \%$; medium molecular weight chitosan with Brookfield viscosity (1\% in $1 \%$ acetic acid) of $200 \mathrm{cP}$ and deacetylation degree of 75-85\%; high molecular weight chitosan with Brookfield viscosity ( $1 \%$ in $1 \%$ acetic acid) of $800 \mathrm{cP}$ and deacetylation degree $>75 \%$ were the selected polymers for microsphere preparation. For analytical method, High Pressure Liquid Chromatography (HPLC) grade acetonitrile and methanol were purchased from Sigma Aldrich (Steinheim, Germany). For anesthesia, a mixture of Rompun ${ }^{\mathbb{B}}$ (Bayer Healthcare, Turkey) and Ketalar ${ }^{\mathbb{B}}$ (Pfizer Drug Co., Ltd., Turkey) were used. For the determination of tumor necrosis factor (TNF)- $\alpha$, interleukin (IL)-1 $\beta$ and IL-6 levels, Assay Max Elisa Kits were used purchased from AssayPro (Montana, U.S.A.). All other chemicals used in the experiments were reagent grade and were used without further purification.

Preparation of Microsphere Formulations Chitosan microspheres containing atorvastatin calcium was prepared by spray drying method. Briefly, the polymer, chitosan, having three different molecular weights as low, medium and high was dissolved in acetic acid solution $(1 \%, \mathrm{v} / \mathrm{v})$ at the concentration of $1 \%(\mathrm{w} / \mathrm{v})$. The active ingredient, atorvastatin calcium, at the ratio of $10 \%$ with respect to the polymer weight was added to the chitosan solution after preparing its solution in methanol. The dispersion was than homogeneously mixed with Ultra Turrax T25 at $11000 \mathrm{rpm}$ for $1 \mathrm{~min}$ 
and afterwards, it was continuously stirred over a magnetic stirrer during spray drying process. The flow rate of the spray dryer was set as $1 \mathrm{ml} / \mathrm{min}$ though a $0.5 \mathrm{~mm}$ nozzle. The inlet temperature was set as $120^{\circ} \mathrm{C}$ and the outlet temperature was determined as $67^{\circ} \mathrm{C}$.

Investigation of the Surface Morphology Microspheres were mounted on metal stubs with a double sided adhesive band and then sputtered with a $150 \AA$ thick layer of gold in a BIORAD Sputter Apparatus. A scanning electron microscope (Jeol-SEM ASID-10 Device in $20 \mathrm{kV}$ ) was used to evaluate the surface characteristics of the microspheres within the magnification range of $\times 1500-2000$

Quantification of Atorvastatin Calcium In order to quantify the amount of atorvastatin calcium from microsphere formulations, a high pressure liquid chromatography (HPLC) method has been developed. In this method, the analytical column is Manchery Nagel $\mathrm{C}_{18}$ column $(250 \times 4.6 \mathrm{~mm} ; 5 \mu \mathrm{m})$. The mobile phase is consisting of $50 \mathrm{~mm} \mathrm{NaH} \mathrm{PO}_{4}$ $(\mathrm{pH} 4.5)$ : acetonitrile : methanol $(3: 3: 4, \mathrm{v} / \mathrm{v} / \mathrm{v})$ at the flow rate of $1 \mathrm{ml} / \mathrm{min}$ The UV detection wavelength was set at $250 \mathrm{~nm}$. The method was validated through the parameters of linearity, accuracy, precision, selectivity, and system suitability.

Determination of Encapsulation Efficiency The amount of atorvastatin calcium entrapped into the microspheres was determined over 3 replicates with a method which basically depends on the method described previously by Gavini et $a l^{23)}$ Briefly, certain amount of microspheres containing atorvastatin calcium were accurately weighed and mixed on a magnetic stirrer with dichloromethane (DCM) for $48 \mathrm{~h}$. Two milliliters of this solution is transferred in to an eppendorf tube and DCM was evaporated under nitrogen gas. Two milliliters of methanol is added over the residue and vortexed for $15 \mathrm{~min}$. Afterwards, this mixture is filtered though $0.45 \mu \mathrm{m}$ polytetrafluoroethylene (PTFE) filters. The amount of atorvastatin was then analyzed with the validated HPLC method described above.

In-Vitro Release The in-vitro release profiles of atorvastatin calcium from microsphere formulations were investigated in $30 \mathrm{ml}$ of $\mathrm{pH} 6.8$ phosphate buffer solution in a horizontal shaker. Certain amount of microspheres were accurately weighed and suspended in the release medium at $37 \pm 0.5$ ${ }^{\circ} \mathrm{C}$. The release profiles of the microsphere formulations were investigated over six different flasks for all formulations. The rotation speed of the horizontal shaker was set at $50 \mathrm{rpm}$. One milliliter of sample was withdrawn from the release medium and replaced immediately with the fresh medium. The samples were filtrated from $0.45 \mu$ m nylon filters and analyzed with the HPLC method that was previously described.

In-Vivo Animal Model The efficiency of chitosan microspheres containing atorvastatin calcium has been investigated in an experimental spinal cord trauma model in Sprague-Dawley (SD) rats. The experimental procedure for in-vivo trials has been approved by the Local Ethical Committee of Ankara Hospital with the protocol number 06/06/2008-0289. The SD rats weighing $200-250 \mathrm{~g}$ were randomly and blindly allocated into four experimental groups as summarized in Table 1. The surgical procedure was performed under general anesthesia induced by intramuscular $10 \mathrm{mg} / \mathrm{kg}$ xylazine (Bayer, Istanbul, Turkey) and $60 \mathrm{mg} / \mathrm{kg}$ ketamine hydrochloride (Parke Davis, Istanbul, Turkey). Rats were placed in prone position. After T6 through T10 midline skin incision, paravertebral muscles were dissected. T7 through T9 spinous processes were removed, and laminectomy was performed. The dura was left intact. Spinal cord contusion injury was produced by the weight drop method described previously by Bethea et al. ${ }^{24)}$ The microsphere formulations were implanted into the laminectomy area just after the introduction of trauma to the SD rats. Representative steps of the surgical procedure are shown in Fig. 1. After surgical and traumatic interventions, the surgical wound was closed in layers with silk sutures. Twentyfour hours after trauma, anesthesia was reintroduced. Animals were placed in prone position. The skin was opened, and the dura was incised longitudinally above the laminectomized spinal cord. Spinal cord samples $(1 \mathrm{~cm})$ were obtained from operated spinal cord area after the animals were sacrificed. Tissue samples were kept in $-196^{\circ} \mathrm{C}$ (liquid nitrogen) until biochemical evaluation.

Functional Evaluation The functional evaluations of the experimental groups were conducted on Day-1, -3 and -5 after spinal cord injury by using inclined plane technique of Rivlin and Tator and a modified version of the Tarlov Grading Scale. ${ }^{25)}$ The parameters used for the evaluation of the animals according to the Tarlov Grading Scale are briefly summarized in Table 2. For the inclined plane evaluations, the degree of the plane that the animals can stand for at least $5 \mathrm{~s}$ was recorded. The scores of the animals were the average scores recorded by two different neurosurgeons that were blinded to the study.

Determination of Lipid Peroxidation Ratio The interaction between free radicals and biochemical substances rapidly occurs in the body. Lipid peroxidation is one of the most significant examples for this interaction. Thiobarbituric acid (TBA) reaction is generally used to determine malondialdehyde (MDA), the end product of lipid peroxidation reaction. ${ }^{26)}$ The final product of lipid peroxidation, MDA, is a volatile substance which can easily evaporate. As a result of this evaporation, it causes the polymerization of the membrane structure. Finally, some of the membrane properties such as ion transport, regulation of enzyme activity, stabilization of the membrane surface and ability to change shape are lost. The membrane is destabilized by lipid peroxidation, loses its property to form a potential, vascular permeability increases and as a result of excess accumulation of $\mathrm{Ca}^{2+}$, cell death occurs. ${ }^{26}$ ) Thirty rats ( $n=6$ for each individual group) were used for the determination of lipid peroxidation level. The lipid peroxidation per gram of wet tissue in nmol was calculated over the MDA amount. MDA is an end product of the thiobarbituric acid reaction, which is used as an indirect parameter for the lipid peroxidation level. Weighed tissue in $100 \mathrm{~mm}$ $\mathrm{KH}_{2} \mathrm{PO}_{4}$ ( $\mathrm{pH} 7.0$ ) buffer was homogenized in an ice bath then $0.25 \mathrm{ml}$ of homogenates ( $10 \%$ concentration) were mixed with $1.5 \mathrm{ml}$ of $1 \% \mathrm{H}_{3} \mathrm{PO}_{4}$ and $0.5 \mathrm{ml} 0.8 \%$ TBA and stored in boiling water for $60 \mathrm{~min}$. After cooling and adding $2 \mathrm{ml} n$-butanol to the tubes, they were vortexed at $2000 \mathrm{rpm}$ for $30 \mathrm{~s}$ and for $30 \mathrm{~min}$ at $2500 \times \boldsymbol{g}$ centrifuged. Color in $n$-butanol phase was read at $532 \mathrm{~nm}$ in spectrophotometer (Shimadzu UV 1700). The amount of lipid peroxide was calculated by using 1,1,3,3-tetramethoxypropane as standard. Each assay was repeated at least twice. Lipid peroxide levels were expressed as nanomoles per gram of tissue. ${ }^{26,27)}$

Determination of Tumor Necrosis Factor-Alpha (TNF- $\alpha$ ), Interleukin-1 Beta (IL-1 $\beta$ ) and Interleukin-6 (IL-6) Levels Spinal cords from
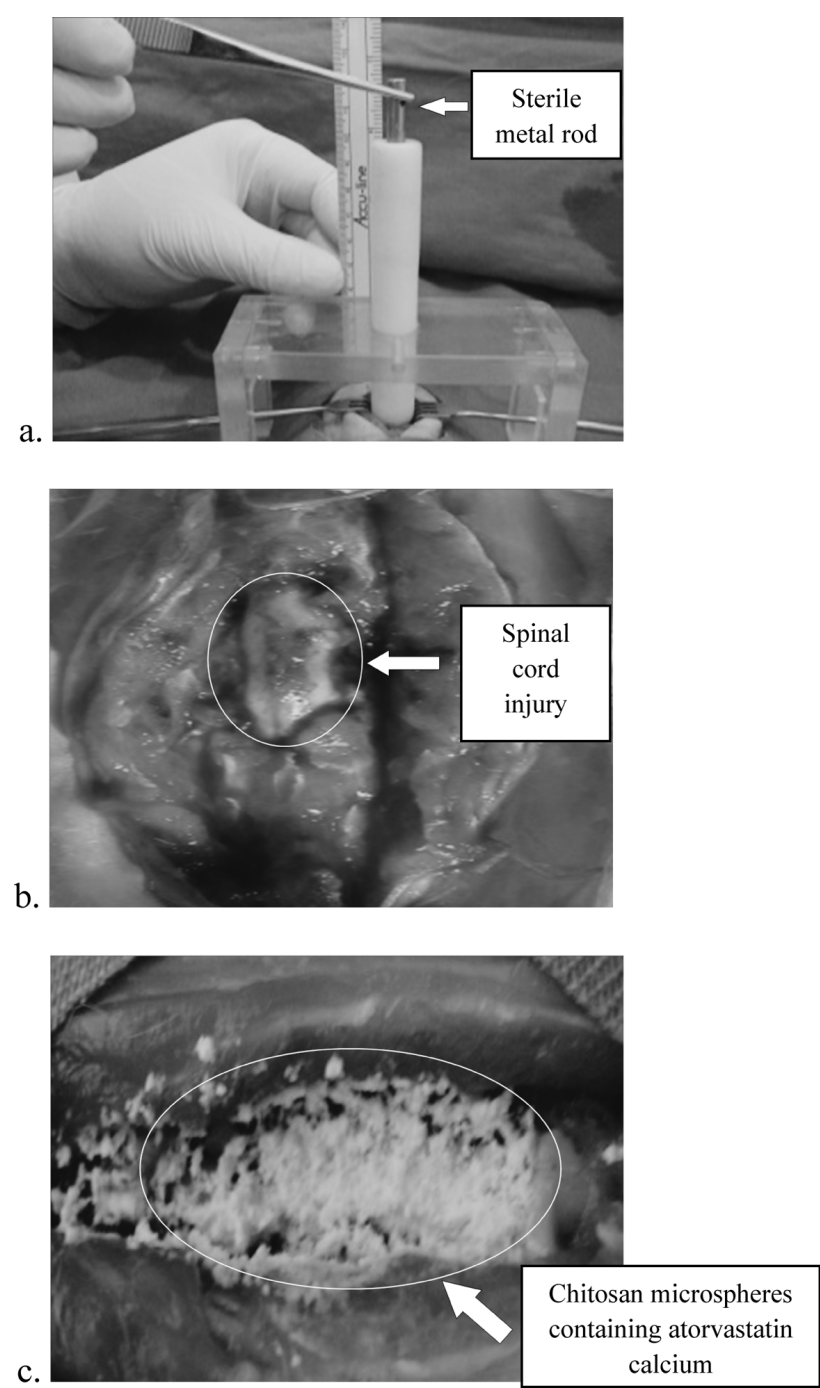

Fig. 1. Representative Scenes from the Surgery

(a) The formation of spinal cord injury, (b) traumatic spine after injury, (c) implantation of the chitosan microspheres after trauma. 
the sacrificed animals were weighed and homogenized $(10 \% \mathrm{w} / \mathrm{v})$ on ice in $25 \mathrm{~mm}$ Tris $\mathrm{pH} 7$ containing $150 \mathrm{~mm} \mathrm{KCl}$ using Omnimixer homogenizer at $3000 \mathrm{rpm}$. An aliquot from the homogenate was set for MDA measurements. The rest of the homogenate was centrifuged at $12000 \times \boldsymbol{g}$ at $+4{ }^{\circ} \mathrm{C}$ for $25 \mathrm{~min}$. The supernatant was used for enzyme-linked immunosorbent assay (ELISA) assays and protein concentration determined by Bradford assay.

The levels of TNF- $\alpha$, IL- $1 \beta$ and IL- 6 were measured with a commercially available sandwich enzyme-linked immunosorbent assay-ELISA kits, which are specific for each of these cytokines individually, from AssayMax according to the procedure recommended by the manufacturer. In brief, $50 \mu 1$ aliquots of sample or standard were pipetted into the wells of a microtiter plate that had been coated with an antibody specific for rat TNF- $\alpha$, IL- $1 \beta$ and IL- 6 and incubated for $2 \mathrm{~h}$ at room temperature. After washing the wells, $50 \mu 1$ of biotinylated TNF- $\alpha$, IL- $1 \beta$ and IL- 6 antibodies were added to each well and incubated for $2 \mathrm{~h}$. At the end of $2 \mathrm{~h}$ the wells were washed, decanted and $50 \mu \mathrm{l}$ of Streptavidin-Peroxidase Conjugate were added per well and incubated for $30 \mathrm{~min}$. After a third incubation and washing to remove all the unbound enzyme, color was developed by addition of stabilized chromogen tetramethylbenzidine, a stop solution added and the intensity of the colored product quantified spectrophotometrically using Spectramax M2 micro plate reader from Molecular Devices at $540 \mathrm{~nm}$.

Ultrastructural Evaluation The tissue samples are resected from the traumatic region of the spine $24 \mathrm{~h}$ after trauma. The tissue samples were examined by an investigator who was blinded to the study protocol by transmission electron microscopy (TEM). For TEM examination; the tissue samples were fixed in $2.5 \%$ gluteraldehyde for $6 \mathrm{~h}$, washed in phosphate buffer ( $\mathrm{pH} 7.4)$, post-fixed in $1 \%$ osmium tetroxide in phosphate buffer $(\mathrm{pH} 7.4)$ for $2 \mathrm{~h}$ and dehydrated in increasing concentrations of alcohol. Then, the tissues were washed with propylene oxide and embedded in epoxy-resin embedding media. Semi-thin sections about $2 \mu \mathrm{m}$ in thickness and ultra thin sections about $60 \mathrm{~nm}$ in thickness were cut with a glass knife on a LKBNova (LKB-Produkter AB, Bromma, Sweden) ultrotome. The semi-thin sections were stained with methylene blue and examined by a Nikon Optiphot (Nikon Corp., Tokyo, Japan) light microscope. Following this examination, the tissue blocks were trimmed, their ultra thin sections were taken by the same ultratome and they were stained with uranyl acetate and lead citrate. Following staining, all the ultra thin sections were examined by Jeol JEM 1200 EX and Jeol 1400 (Jeol Ltd., Tokyo, Japan) transmission electron microscopes. The electron micrographs were taken by the Orius SC 1000 CCD camera of Jeol 1400 transmission electron microscope.

Statistical Analysis For the evaluation of the statistical differences between experimental groups, one way ANOVA test has been used at the significance level $p=0.05$ (SPSS 16.0 software). The comparison within the experimental groups was investigated with Bonferroni Test. All the data were expressed as means \pm standard deviation (S.D.) and $p<0.05$ was

Table 1. The Experimental Groups and Surgical Procedure

\begin{tabular}{lccl}
\hline \hline & Laminectomy & Trauma & Procedure after trauma \\
\hline Group A & + & - & No application \\
Group B & + & + & No application \\
Group C & + & + & $\begin{array}{l}\text { Implantation of empty } \\
\text { chitosan microsphere }\end{array}$ \\
Group D & + & + & $\begin{array}{l}\text { Implantation of chitosan } \\
\text { microspheres containing } \\
\end{array}$ \\
& & & a torvastatin calcium \\
& & & $(1 \mathrm{mg} / \mathrm{kg})$ \\
& & &
\end{tabular}

accepted as statistically significant.

\section{Results}

Preparation Efficiency The preparation efficiencies of all three types of microsphere formulations prepared with chitosan polymer having three different molecular weights (low, medium and high) were determined. The preparation efficiencies were recorded as $66.28 \%, 52.77 \%$ and $45.37 \%$ for polymer types low, medium and high, respectively. The formulations were prepared over a single batch; therefore the data are represented only by a single resulting value.

Surface Morphology The surface morphologies of the formulations were investigated by SEM as previously described. The SEM images show that there are still some drug particles existing over the surface of the microspheres prepared with high molecular weight chitosan. The results are in correlation with the encapsulation efficiency determinations. The microspheres were regular in shape and there are no porous structures existing in the microsphere formulations. The SEM images of the three formulations are shown in Fig. 2.

Quantification of Atorvastatin Calcium A reversedphase high-performance liquid chromatographic method was optimized for the determination atorvastatin calcium encapsulated in chitosan microspheres. Under the optimum conditions atorvastatin calcium is eluted in $5.9 \mathrm{~min}$ (Fig. 3). Afterwards, the optimized method was validated through the parameters of system suitability, limit of detection (LOD), limit of quantification (LOQ), linearity, accuracy, precision, and selectivity. Firstly, system suitability of the method was assessed by ten replicate analyses of atorvastatin calcium. The retention time repeatability, capacity factor, theoretical plate number and peak asymmetry were $0.6 \%$ RSD, 5.1, 4461 and 1.1, respectively. All of these values were within acceptable criterion, therefore the method was found suitable for the analyses of atorvastatin calcium.

The LOD and LOQ were estimated on the basis of the results for three replicates of atorvastatin calcium at different

Table 2. Tarlov Grading Scale ${ }^{25)}$

\begin{tabular}{cl} 
Point & \multicolumn{1}{c}{ Observed motor functions } \\
Grade 1 & $\begin{array}{l}\text { No voluntary movement } \\
\text { Minimal voluntary hind-limb movements but unable } \\
\text { to stand }\end{array}$ \\
Grade 3 & $\begin{array}{l}\text { Able to stand but unable to walk } \\
\text { Able to walk with spasticity or incoordination of the hind } \\
\text { limbs } \\
\text { Grade 5 }\end{array}$ \\
\end{tabular}
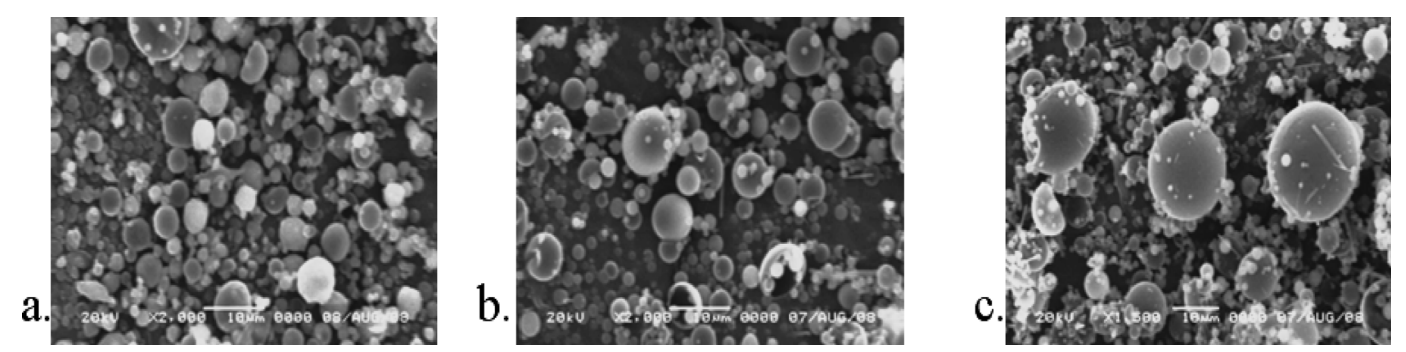

Fig. 2. SEM Images of the Microsphere Formulations Containing Atorvastatin Calcium

Microspheres represented in the SEM images are prepared with three different type of chitosan depending on its molecular weight as (a) low molecular weight; (b) medium molecular weight and (c) high molecular weight. 
levels, considering a signal-to-noise ratio of 3 and 10, respectively. The LOD and LOQ values were found to be as 30 and $90 \mathrm{ng} \cdot \mathrm{ml}^{-1}$, respectively.

The calibration curve was linear in the range from 0.25 to $8 \mu \mathrm{g} \mathrm{ml}^{-1}$. The linear calibration curve between the peak area and the concentration of the atorvastatin calcium was established by linear regression. The regression equation of calibration curve was $y=1.0586 x-0.0999$ where $y$ is peak area and $x$ is concentration. The correlation coefficient $\left(R^{2}\right)$ was calculated as 0.9996 indicating the goodness of the linearity.

The precision of the method was investigated with respect to injection repeatability and intermediate precision. The injection repeatability of the system was evaluated by ten consecutive injections. The RSD values of retention time was $0.6 \%(<1 \%)$. This result indicates that the system had good injection repeatability. To assess intra-day precision, six spiked samples at three concentration levels were prepared and analyzed twice. For inter-day precision, three different daily renewals of the intraday precision were carried out. The RSD values of intra- and inter-day studies varied from 1.2 to $1.8 \%$ showed that the intermediate precision of the method was satisfactory.

The accuracy of a method is determined by calculating the percentage relative error between the measured mean concentrations and added concentrations (Bias \%). Intra-day and inter-day accuracies (Bias \%) were varied from 0.5 to $2.6 \%$ which shows good accuracy.

The selectivity of the method was evaluated by analyzing blank microsphere. In the evaluation of the selectivity, atorvastatin calcium was well resolved from baseline (Fig. 3) and there was no matrix effect from blank microsphere at the same time of atorvastatin calcium.

Determination of the Encapsulation Efficiency The encapsulation efficiencies for chitosan microsphere formulations were determined over three replicates. Atorvastatin encapsulation efficiencies for the formulations prepared with low, medium and high were calculated as $18.359 \pm 0.013 \%$; $17.535 \pm 0.002 \%$ and $12.450 \pm 0.009 \%$, respectively in terms of mean \pm S.D.

In-Vitro Release The in-vitro release profiles of the microsphere formulations prepared with different types of chitosan [different molecular weights as low (L), medium $(\mathrm{M})$ and high $(\mathrm{H})]$ were investigated. The release profiles were only investigated for $24 \mathrm{~h}$. As seen from the release profiles, the molecular weight of the chitosan clearly affects the release of atorvastatin calcium (Fig. 4), as well as the specific surface area. As the surface area decreases with the increasing molecular weight, a more rapid release was observed with low molecular chitosan microsphere formulations. The most desired release rate ( $24 \mathrm{~h}$ release) was achieved in the medium molecular weight chitosan formulations $(91.42 \%$ in $24 \mathrm{~h}$ ) and this formulation was carried forward to in-vivo experiments.

Functional Evaluation The modified Tarlov Scores of the animals in all experimental groups were recorded over 6 animals per each group after evaluation by an investigator who was blinded to the study protocol. The scores as expressed in Fig. 5 with standard error bars for each group. The comparison of the results for group D vs. group B and group $\mathrm{D} v s$. group $\mathrm{C}$ reveal statistically significant differences between groups with $p$ values $<0.05$. Also the scores

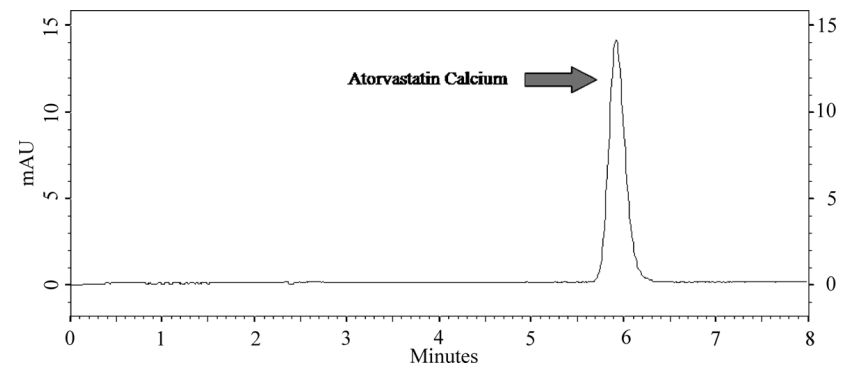

Fig. 3. Representative Chromatogram of the Atorvastatin Calcium $(5 \mu \mathrm{g} / \mathrm{ml})$ at the Optimum Conditions (Mobile Phase Consisting of $50 \mathrm{~mm}$ $\mathrm{NaH}_{2} \mathrm{PO}_{4}(\mathrm{pH} 4.5)$ : acetonitrile : methanol $(3: 3: 4, \mathrm{v} / \mathrm{v} / \mathrm{v}), 1 \mathrm{ml} / \mathrm{min}$ for Flow Rate and $250 \mathrm{~nm}$ for Detection Wavelength)

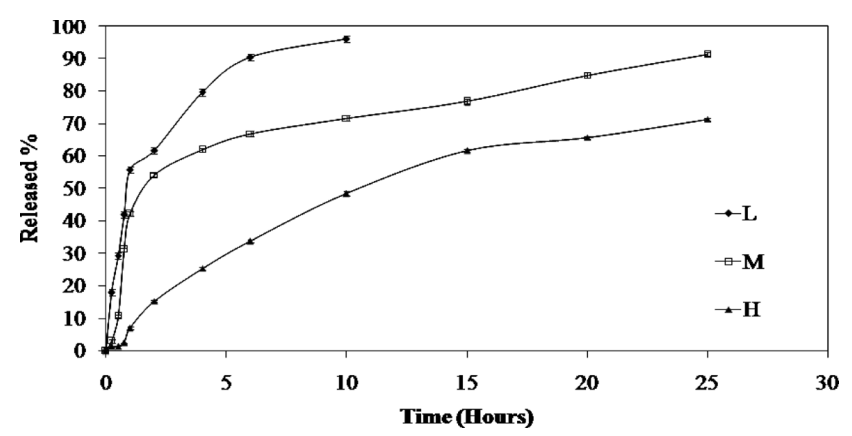

Fig. 4. In-Vitro Release Profiles of the Microsphere Formulations

The points are represented with mean \pm S.D. The profiles are expressed with legends $\mathrm{L} ; \mathrm{M}$ and $\mathrm{H}$ indicating the molecular weight type of the chitosan polymer used in the microsphere preparation. $\mathrm{L}=$ low molecular weight; $\mathrm{M}=$ medium molecular weight; $\mathrm{H}=$ high molecular weight

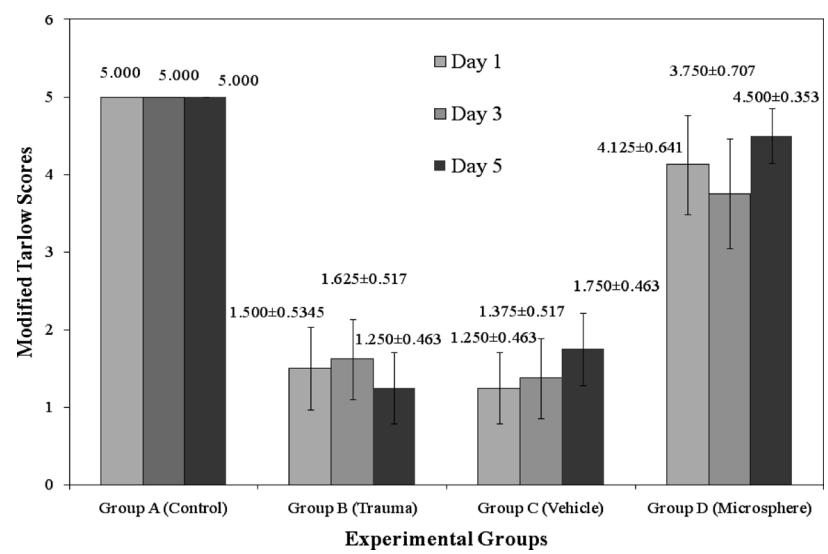

Fig. 5. Modified Tarlov Scores of the Experimental Groups Are Expressed in Terms of MeantS.D. $(n=6)$

The administration of atorvastatin loaded chitosan microspheres significantly elevated the scores of the animals in group D when compared with the scores of the animals in group B and group C ( $p<0.05$ for all $3 \mathrm{~d})$.

of day-1, -3 and -5 of each group were compared with oneway ANOVA test in order to investigate if there is a significant difference between the scores of the same group on different days. The result for this comparison revealed no significant difference between scores of the same group on different days $(p>0.05)$ The functional examinations of the animals in group D result in higher scores on day-1, -3 and -5 indicating that atorvastatin treatment attenuates functional dysfunction after spinal cord injury.

Determination of Lipid Peroxidation Ratio The lipid peroxidation ratios of the experimental groups are expressed 


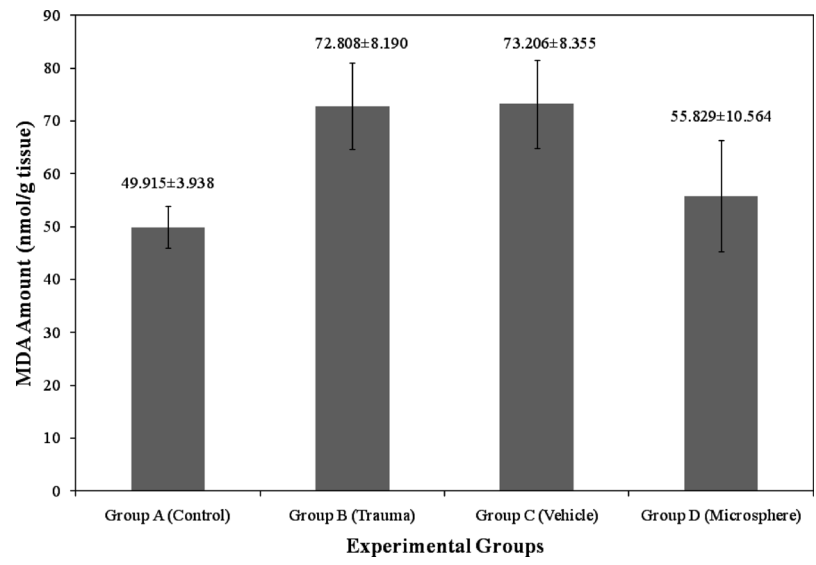

Fig. 6. MDA Amounts for the Experimental Groups Are Expressed in Terms of $\mathrm{nmol} / \mathrm{g}$ Tissue (Mean \pm S.D.; $n=6$ )

After the comparison of the mean values with Bonferroni post-hoc test, statistically significant difference was determined in terms of MDA amounts between group D (atorvastatin microspheres implanted after trauma) and group B (no treatment after trauma); $p<0.05$. On the other hand no statistical difference has been observed between group B and group C (empty microspheres after trauma); indicating that the vehicle has no effect on MDA values after trauma; $p>0.05$

in terms of $\mathrm{nmol} / \mathrm{g}$ tissue over the MDA amount (Fig. 6). After the analysis of the statistical difference between 4 groups with one-way ANOVA test, statistically significant difference has been established at the significance level $p<0.05$. The post-hoc comparisons of the groups were evaluated with the Bonferroni test. Implantation of the atorvastatin loaded chitosan microspheres in group D significantly reduced lipid peroxidation ratio $(55.829 \pm 18.923$; mean \pm S.D.) with respect to positive control group, in which no treatment has been introduced after trauma (group B) $(72.808 \pm 11.248$; mean \pm S.D. $)(p=0.01)$. For the investigation of vehicle effect, the lipid peroxidation ratios of the group $\mathrm{C}$ (empty chitosan microsphere implantation after trauma) and group B were individually compared again with Bonferroni test for no statistical difference has been found within these two groups $(p=1.00)$. In addition, statistical comparison of group A with group B indicated that only surgery caused no effect on MDA values $(p=0.01)$.

Determination of TNF- $\alpha$; IL- $1 \beta$ and IL-6 Levels The levels of the three major cytokines are determined at 24 after trauma. The results for IL- $1 \beta$ and IL- $6(\mathrm{pg} / \mathrm{ml})$ of the experimental groups are expressed in the same figure (Fig. 7). It is a clear fact that trauma causes a significant elevation in both IL- $1 \beta$ and IL- 6 values when the results for group A (control) and group B (trauma) are compared with each other ( $p=$ 0.033 and 0.043 for IL-1 $\beta$ and IL- 6 respectively). On the other hand, no significant difference has been observed for the administration of the empty chitosan microspheres on IL$1 \beta$ and IL- 6 values when the results of group B (trauma) and group $\mathrm{C}$ (vehicle) are compared with each other $(p=1.000$ for both IL-1 $\beta$ and IL-6). However, a significant attenuation in IL-1 $\beta$ and IL-6 levels after the administration of atorvastatin loaded chitosan microspheres in group $\mathrm{D}$ with respect the group B (trauma) ( $p=0.005$ and 0.026 for IL- $1 \beta$ and IL-6 respectively). Similar to the results of IL- $1 \beta$ and IL- 6 cytokine levels, when the TNF- $\alpha$ levels of group D (microsphere) and group B (trauma) are compared with each other, a significantly attenuation in group D (microsphere) has been observed after administration of atorvastatin loaded chitosan

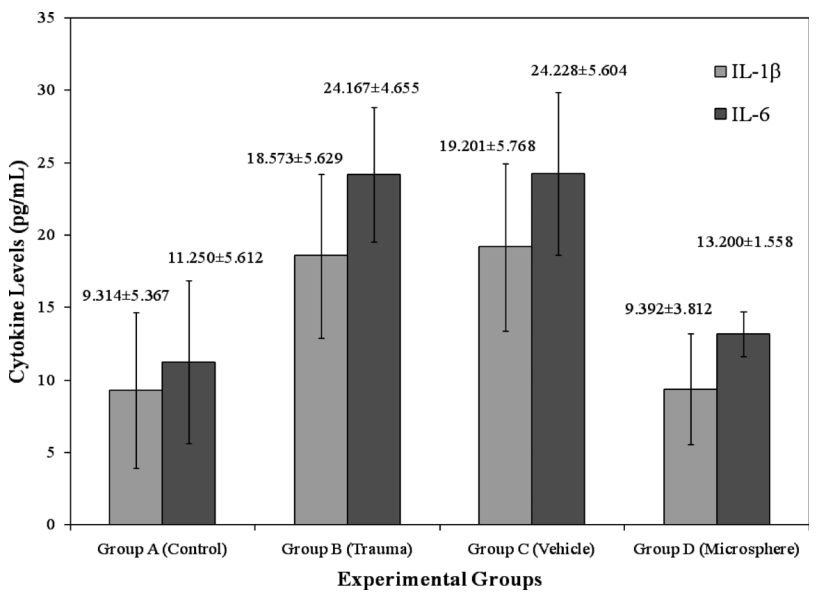

Fig. 7. IL-1 $\beta$ and IL-6 Levels for the Experimental Groups

The results are expressed in terms of $\mathrm{pg} / \mathrm{ml}$ with mean \pm S.D.; $n=6$. When the results of group A (control) and group B (trauma) were compared with each other, the fact that trauma causes statistically significant elevation in both IL- $1 \beta$ and IL-6 values $(p=0.033$ and 0.043 for IL- $1 \beta$ and IL- 6 respectively). On the other hand it is a clear fact that after the administration of atorvastatin loaded chitosan microspheres in group D with respect the group B (trauma), there exists a significant attenuation in IL- $1 \beta$ and IL-6 levels ( $p=0.005$ and 0.026 for IL- $1 \beta$ and IL- 6 respectively).

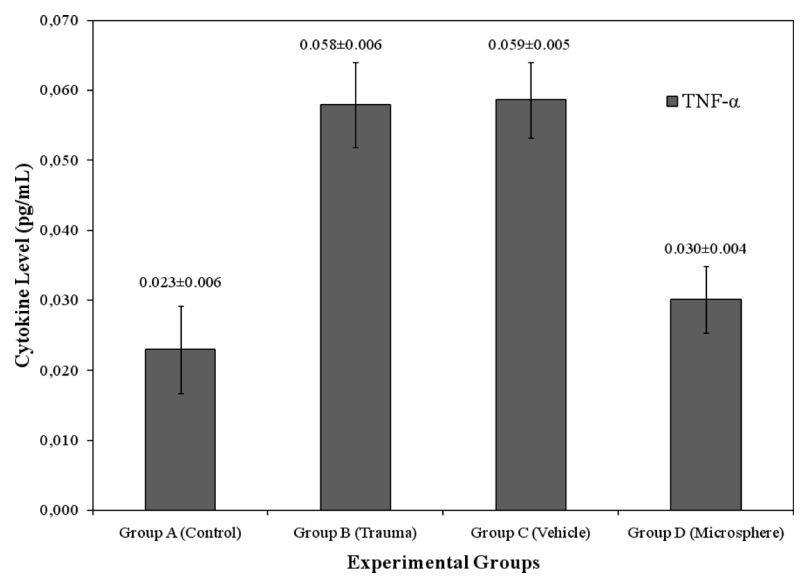

Fig. 8. TNF- $\alpha$ Levels for the Experimental Groups

The results are expressed in terms of $\mathrm{pg} / \mathrm{ml}$ with mean \pm S.D.; $n=6$. When the TNF- $\alpha$ levels of group D (microsphere) and group B (trauma) are compared with each other, a significantly attenuation in group $\mathrm{D}$ (microsphere) has been observed after administration of atorvastatin loaded chitosan microspheres $(p=0.000)$.

microspheres $(p=0.000)$ (Fig. 8).

Ultrastructural Evaluation In TEM examination of the spinal cord samples of group A (control) in which laminectomy has been done, gray and white maters of the tissue samples were found as normal. Organelles, neurons, membranes and perineuronal tissues showed no pathological changes. Only a few number of mild separations have been observed, which are probably due to the delayed fixation of the tissue during preliminary procedure. On the other hand for group B (sham) and group C (vehicle), ultrastructural pathological changes have been observed in small, medium and large sized myelinated axons. The severity of these changes was greater in magnitude especially in large sized myelinated axons. Separation in myelin configuration and interruption in myelin configuration were also present. In group D (microsphere), although the intracellular vacuoles were present in the cytoplasm of the neurons, they had smaller dimensions than group B and group C. In all of the neurons in group D, cell membranes were normal (Fig. 9). 

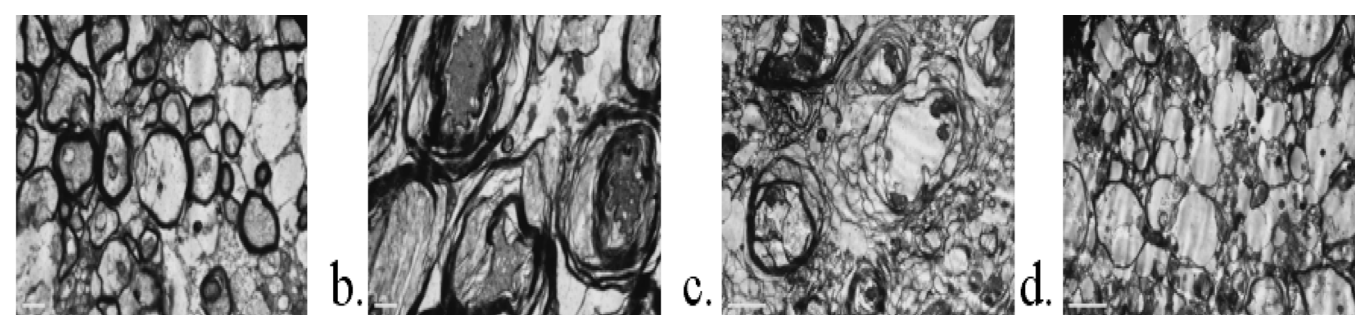

Fig. 9. Transmission Electron Microscopy (TEM) Photographs of the Spinal Cord Tissues in Experimental Groups

\section{Discussion}

Chitosan is one of the most promising natural polymers used in pharmaceutical field. Enabling the controlled release of the active ingredient from the formulation is the outstanding property of chitosan that makes it desirable to be used in many novel drug delivery systems. ${ }^{2-32}$ Depending on the molecular weight of chitosan, the released amount of the active ingredient may easily be controlled. Our results are in good correlation with the literature findings about the effect of molecular weight on drug release from the pharmaceutical formulations. ${ }^{33)}$ As the molecular weight of the chitosan is increased, the release of atorvastatin from chitosan microspheres significantly decreased. The statistical analysis of the release data with one-way ANOVA test indicated that the release profiles of the three microsphere formulations are significantly different from each other $(p<0.05)$. The encapsulation efficiency results reveal that as the molecular weight of the chitosan in the formulation increases, the encapsulation tendency of atorvastatin is decrease significantly $(p<$ $0.05)$. These results do correlate with the surface morphology investigations. As seen in Fig. 2, the crystals exist which are assumed to be the un-encapsulated atorvastatin powder on the surface of the microspheres. Although the crystalline structures are assumed to be very tiny with respect to the amount of totally excluded atorvastatin, this might be due to the viscous structure of the chitosan solution of high molecular weight type. As the molecular weight of the chitosan solution increases, the water insoluble atorvastatin becomes more sparingly suspended in the chitosan solution. In other words, a more dilute suspension of atorvastatin was prepared with high molecular weight chitosan. Therefore, encapsulation efficiency was decreased in high molecular weight formulations.

A reversed-phase HPLC method was optimized for the determination atorvastatin calcium encapsulated in chitosan microspheres. Under the optimum conditions atorvastatin calcium was eluted in $5.9 \mathrm{~min}$. Then the method optimized was validated through the parameters of system suitability, limit of detection (LOD) and quantification (LOQ), linearity, accuracy, precision, and selectivity. According to the results obtained from validation studies, the analytical method developed for the quantification of atorvastatin from chitosan microspheres has been found as suitable, linear, accurate, precise and selective.

The functional evaluations were investigated 1,3 and $5 \mathrm{~d}$ after trauma. The animals in group D, in which atorvastatin loaded microspheres were implanted, modified Tarlov Scores of the animals were significantly higher with respect to the trauma (group B) and vehicle (group C) groups in all $3 \mathrm{~d}$ $(p<0.05)$. The effect of time on functional recovery of animals in groups yielded in no significant difference between days $(p>0.05)$

Two different mechanisms govern the tissue loss after spinal cord injuries (SCI) which are primary injury that is followed by secondary injury. Primary injury (PI) is the events that cause the contusion, compression or laceration of the neuronal tissues in the medulla spinalis. In other words, it is the mechanical injury formed just at the traumatic event. $^{34,35)}$ On the other hand secondary injury (SI) immediately starts just after primary insult. It may be described as the cascade of events involving many different metabolic and biochemical events resulting in tissue destruction. After PI hemorrhage, edema, formation of axonal and neuronal cyst and infarct following demyelinization occurs. Neurogenic shocks, excitotoxicity, liquid-electrolyte imbalance, increase in intracellular calcium level, free radical theory, apoptosis and anti-inflammatory responses are the main mechanisms underlying secondary injury. ${ }^{36)}$

Secondary tissue damage following compression injury involves inflammation depending on the promotion of tissue edema. Many molecules that allow vascular permeability and induce cellular fluid loss are induced by inflammatory cytokines. ${ }^{37)}$ Schnell et al. have shown that direct injection of IL-1 $\beta$ into spinal cord resulted in enhanced vascular permeability and lymphocyte recruitment. ${ }^{38)}$ In another study by Pan et al., it has been demonstrated that within $15 \mathrm{~min}$ time after contusion of rat spinal cord, inflammatory cytokine RNAs are induced. RNAse protection assays showed significantly enhanced levels of IL- $1 \alpha$, IL- $1 \beta$, IL- 6 and TNF- $\alpha$ mRNAs by $15 \mathrm{~min}$. This induction of cytokine mRNAs was consistent with the cytokine action pattern with IL-1 and TNF- $\alpha$ peaking first, followed by IL- 6 mRNA. ${ }^{37)}$ Tuna et al. have shown that cytokines such as IL-6 have been secreted by accumulated inflammatory cells in the injured spinal cord. ${ }^{39)}$ In addition, TNF was marked as a significant cytokine that promotes the migration of blood leucocytes into the injured tissue by modulating expression of different surface antigens. ${ }^{40)}$ Regarding the previous literature data, our results do well correlate with the previous findings. The three major cytokine IL-1 $\beta$, IL- 6 and TNF- $\alpha$ levels are significantly reduced after local administration of atorvastatin calcium loaded chitosan microspheres.

It was previously demonstrated that tissue hemorrhage initiates free radical formation and iron compounds catalyze the formation of highly reactive hydroxyl radicals. As a result of these reaction, lipid peroxidation is stimulated. ${ }^{41)}$ The results of this study clearly indicates that although SCI significantly induces malondialdehyde levels with non traumatized group, atorvastatin calcium encapsulated in the chitosan microspheres reduces lipid peroxidation ratio and exerts neuroprotective effects $24 \mathrm{~h}$ after SCI. Previous literature date states that the mechanism underlying the neuropro- 
tective effect of atorvastatin was independent of their cholesterol lowering effects. On the other hand the possible mechanism was explained in the way that, neuroprotection may be due to the modulations in NMDA receptor activity and intracellular calcium dynamics. It was clearly stated that pretreatment of the neuronal cells with atorvastatin significantly reduces intracellular calcium levels and protects cortical neurons from excitotoxic cell death. ${ }^{42}$ That is why, the lipid peroxidation lowering effects of atorvastatin may be related to its capacity to block NMDA receptors, that are endogenous inducers of lipid peroxidation.

Depending on the previous literature data mentioned above, the biochemical parameters for the evaluation of the efficiency of atorvastatin calcium loaded microsphere implantation were set as lipid peroxidation ratio, IL-1 $\beta$; IL-6 and TNF- $\alpha$ levels. Our results showed that SCI markedly increased the levels of these biochemical parameters in rat spine $24 \mathrm{~h}$ after trauma. On the other hand, in treatment group (group D, microsphere), the administration of atorvastatin loaded chitosan microshperes exerts neuroprotective effects and significantly attenuated the levels of these parameters. These results are also supported by the ultrastructural evaluation of the rat spinal cord tissues in the experimental groups.

In summary our results showed that atorvastatin loaded chitosan microsphere administration after SCI, decreases lipid peroxidation, IL- $1 \beta$, IL- 6 and TNF- $\alpha$ levels; improves functional outcome and protects ultrastructural damage in the spinal cord tissue. The results of this study support previous literature data on neuroprotective properties of atorvastatin. ${ }^{17,43,44)}$ Although studies about the neuroprotective effects of atorvastatin exists in literature, ${ }^{13,42,45,46)}$ this was the first study with an atorvastatin formulation on neuroprotective effect evaluation after spinal cord injury. Dose-response studies must be further explored in order to clarify the potential dose in protecting the human spinal cord from traumatic injury.

\section{Conclusion}

This study clearly states that atorvastatin attenuates the degree of damage in the spinal cord tissue after traumatic injury in animals. Up to our knowledge, it is the first time that the efficiency of atorvastatin in a controlled release dosage form is being investigated. Further dose-response studies must be completed in order to clarify the optimum dose of atorvastatin in SCI treatment.

Acknowledgements This study was supported by the Hacettepe University Scientific Research Project Unit with the project number 09-D03301002-4786.

\section{References}

1) Ducker T. B., Kindt G. W., Kempf L. G., J. Neurosurg., 35, 700-708 (1971).

2) Pahan K., Sheikh F. G., Namboodiri A. M., Singh I., J. Clin. Invest., 100, 2671-2679 (1997)

3) Stanislaus R., Pahan K., Singh A. K., Singh I., Neurosci. Lett., 269 $71-74$ (1999).

4) Vollmer T., Key L., Durkalski V., Tyor W., Corboy J., Markovic-Plese S., Preiningerova J., Rizzo M., Singh I., Lancet, 363, 1607-1608 (2004).

5) Paintlia A. S., Paintlia M. K., Khan M., Vollmer T., Singh A. K., Singh I., FASEB J., 19, 1407-1421 (2005).

6) DeKosky S. T., Am. J. Med., 118 (Suppl. 12A), 48-53 (2005).

7) Ringheim G. E., Szczepanik A. M., Curr. Pharm. Des., 12, 719-738 (2006).
8) Hess D. C., Demchuk A. M., Brass L. M., Yatsu F. M., Neurology, 54, 790 - 796 (2000).

9) Vaughan C. J., Delanty N., Basson C. T., CNS Drugs, 15, 589-596 (2001).

10) Moonis M., Kane K., Schwiderski U., Sandage B. W., Fisher M., Stroke, 36, 1298-1300 (2005).

11) Endres M., Laufs U., Liao J. K., Moskowitz M. A., Trends Neurosci., 27, 283-289 (2004).

12) Pannu R., Barbosa E., Singh A. K., Singh I., J. Neurosci. Res., 79, $340-350$ (2005).

13) Pannu R., Christie D. K., Barbosa E., Singh I., Singh A. K., J. Neurochem., 101, 182-200 (2007).

14) Amarenco P., Neurology, 57 (Suppl. 2), S35-S44 (2001).

15) Vaughan C. J., Delanty N., Stroke, 30, 1969-1973 (1999).

16) Hebert P. R., Gaziano J. M., Hennekens C. H., Arch. Intern. Med., 155, $50-55$ (1995).

17) Bosel J., Gandor F., Harms C., Synowitz M., Harms U., Djoufack P. C., Megow D., Dirnagl U., Hortnagl H., Fink K. B., Endres M., J. Neurochem., 92, 1386-1398 (2005).

18) Romoren K., Thu B. J., Evensen O., J. Controlled Release, 85, 215 225 (2002).

19) Rao S. B., Sharma C. P., J. Biomed. Mater. Res., 34, $21-28$ (1997).

20) Hirano S., Hirochi K., Hayashi K., Mikami T., Tachibana H., "Cosmetic and Pharmaceutical Applications of Polymers," ed. by Gebelin C., Cheng T. C., Yang V. C., Plenum Press, New York, 1991, pp. 95104.

21) Sanford P. A., "Chitin and Chitosan," ed. by Skjak-braek G., Anthonsen T., Sanford P., Elsevier Applied Science, London, 1988 pp. 51-69.

22) Peniche C., Arguelles-Monal W., Peniche H., Acosta N., Macromolec. Biosci., 3, 511-520 (2003).

23) Gavini E., Hegge A. B., Rassu G., Sanna V., Testa C., Pirisino G., Karlsen J., Giunchedi P., Int. J. Pharm., 307, 9-15 (2006).

24) Bethea J. R., Castro M., Keane R. W., Lee T. T., Dietrich W. D., Yezierski R. P., J. Neurosci., 18, 3251-3260 (1998).

25) Rivlin A. S., Tator C. H., J. Neurosurg., 47, 577-581 (1977)

26) Freeman B. A., Crapo J. D., Lab. Invest., 47, 412-426 (1982).

27) Maxwell R. E., Long D. M., French L. A., J. Neurosurg., 34, 477-487 (1971).

28) Zhang X., Chen F., Ni J., Drug Deliv., 16, 280-288 (2009).

29) Vodna L., Bubenikova S., Bakos D., Macromol. Biosci., 7, 629-634 (2007).

30) De la Riva B., Nowak C., Sanchez E., Hernandez A., Schulz-Siegmund M., Pec M. K., Delgado A., Evora C., Eur. J. Pharm. Biopharm., 73, 50-58 (2009).

31) Wittayasuporn M., Rengpipat S., Palaga T., Asawanonda P., Anumansirikul N., Wanichwecharungruang S. P., J. Microencapsul., 27, 218 225 (2010).

32) Goycoolea F. M., Lollo G., Remunan-Lopez C., Quaglia F., Alonso M. J., Biomacromolecules, 10, 1736-1743 (2009).

33) Learoyd T. P., Burrows J. L., French E., Seville P. C., Int. J. Pharm., 372, 97-104 (2009).

34) Esmon C. T., FASEB J., 9, 946-955 (1995).

35) Esmon C. T., Blood, 95, 1113-1116 (2000).

36) Tator C. H., Fehlings M. G., J. Neurosurg., 75, 15-26 (1991).

37) Pan J. Z., Ni L., Sodhi A., Aguanno A., Young W., Hart R. P., J. Neurosci. Res., 68, 315-322 (2002).

38) Schnell L., Fearn S., Schwab M. E., Perry V. H., Anthony D. C., J. Neuropathol. Exp. Neurol., 58, 245-254 (1999).

39) Tuna M., Polat S., Erman T., Ildan F., Gocer A. I., Tuna N., Tamer L., Kaya M., Cetinalp E., J. Neurosurg., 95 (Suppl.), 64-73 (2001).

40) Taoka Y., Okajima K., Prog. Neurobiol., 56, 341-358 (1998).

41) Halliwell B., Gutteridge J. M. C., Trends Neurosci., 8, 22-26 (1985).

42) Bosel J., Gandor F., Harms C., Synowitz M., Harms U., Djoufack P. C., Megow D., Dirnagl U., Hortnagl H., Fink K. B., Endres M., J. Neurochem., 92, 1386-1398 (2005).

43) Lu D., Goussev A., Chen J., Pannu P., Li Y., Mahmood A., Chopp M., J. Neurotrauma, 21, 21-32 (2004).

44) Zacco A., Togo J., Spence K., Ellis A., Lloyd D., Furlong S., Piser T., J. Neurosci., 23, 11104-11111 (2003).

45) Clarke R. M., Lyons A., O’Connell F., Deighan B. F., Barry C. E., Anyakoha N. G., Nicolaou A., Lynch M. A., J. Biol. Chem., 283, 1808-1817 (2008)

46) Lee S. H., Kim Y. H., Kim Y. J., Yoon B. W., J. Neurol. Sci., 275, 64 68 (2008) 